glucose or galactose. Sucrose challenge led to profuse diarrhoea with identifiable sucrose in the stool thus confirming the diagnosis.

All four foods given before the fructose-based formula contained large amounts of maltose or malto-dextrins which need maltase for complete digestion; there was no sucrose in them and none was added at any stage. Ostermilk complete formula contains more maltose than lactose and presumably the lactose was swept through the bowel with the osmotic diarrhoea caused by maltose. Since then we have tested Maxijul $10 \mathrm{~g} / 100 \mathrm{ml}$ in water using several methods considered to be specific for glucose. The Beckman glucose analyser (glucose oxidase), gave a glucose concentration of $310 \mathrm{mmol} / \mathrm{l}$. The other three glucose analysers (Instrumentation Laboratories IL 919: glucose oxidase, Yellow Springs Instruments 23 AM: glucose oxidase, and Union Carbide Centrifichem 400: hexokinase) gave glucose concentrations of $6 \cdot 5,6 \cdot 6$, and $6.6 \mathrm{mmol} / \mathrm{l}$ respectively.

Chromatography has shown that Maxijul contains free glucose, maltose, and maltotriose in addition to other glucose polymers. The high faecal glucose level with the Beckman analyser was not the result of crossreaction with maltose, as maltose at a concentration of $10 \mathrm{mmol} / \mathrm{l}$ gave very low glucose readings with all four analysers. We think that free glucose in Maxijul is greatly overestimated if the Beckman analyser is used; this problem would not arise with blood glucose which the instrument is designed to measure.

Maltose or malto-dextrins of higher molecular weight needing maltase for complete digestion are present in many specialised infant foods, and small quantities of maltose identified chromatographically in stools may be significant.

We thank Dr T A H MacDonald and Professor F Cockburn for permission to report this case, and $\mathrm{Mr} \mathrm{W}$ Borland for help with the biochemical investigations.

$$
\begin{array}{r}
\text { J F B DossETOR } \\
\text { Department of Paediatrics, } \\
\text { Queen Elizabeth Hospital, } \\
\text { Gayton Road, } \\
\text { King's Lynn, } \\
\text { Norfolk PE30 4ET } \\
\text { M D CoNNELL } \\
\text { Department of Paediatrics and Biochemistry, } \\
\text { Royal Hospital for Sick Children, } \\
\text { Yorkhill, Glasgow G3 } 8 S J
\end{array}
$$

\section{Circadian patterns of plasma steroids in congenital adrenal hyperplasia}

Sir,

The data reported by Frisch et al. ${ }^{1}$ are extremely interesting. It was known that the great sensitivity of plasma 17-hydroxyprogesterone (17-OHP) concentrations to circadian rhythms, and the effect of divided glucocorticoid doses make it difficult to interpret single plasma values when monitoring treatment. ${ }^{2}{ }^{3}$ It was also known that there is a close correlation between simultaneous plasma determinations of 17-OHP and testosterone in treated and untreated patients with congenital adrenal hyperplasia (CAH), except in pubertal males. ${ }^{4}$ Frisch et al. ${ }^{1}$ did not analyse their results in this way. Certainly Cases 3, 8, 9, and 10 showed obvious parallel changes in plasma 17-OHP and testosterone concentrations after various types of treatment. If strict attention is paid to sampling in relation to the time of day and time of previous glucocorticoid dose, serial measurements of plasma 17-OHP and testosterone are a useful index of control. Such data collected longitudinally over a 3-year period in 19 treated $\mathrm{CAH}$ patients showed a good correlation $(r=0.79)$ between plasma 17-OHP and testosterone concentrations (personal observation).

Frisch et al. ${ }^{1}$ did not say what biochemical measurements they would recommend as reliable and practical indexes of therapeutic control in CAH. It is important to remember that any therapeutic decision in $\mathrm{CAH}$ patients should be taken in the context of clinical parameters of control (growth, skeletal age, signs of puberty or hypercortisolism, regularity of menses, etc.) and levels of plasma renin activity as an index of mineralocorticoid replacement, in addition to the results of plasma or urinary concentrations of adrenal precursor steroids.

\section{References}

1 Frisch H, Parth K, Schober E, Swoboda W. Circadian patterns of plasma cortisol, 17-hydroxyprogesterone, and testosterone in congenital adrenal hyperplasia. Arch Dis Child 1981; 56: 208-13.

${ }^{2}$ Hughes I A, Winter J S D. Application of a serum $17 \mathrm{OH}$-progesterone radioimmunoassay to diagnosis and management of congenital adrenal hyperplasia. $J$ Pediatr 1976; 88: 766-73.

3 Winter J S D. Marginal comment: Current approaches to the treatment of congenital adrenal hyperplasia. J Pediatr 1980; 97: 81-2.

4 Hughes I A, Winter J S D. Relationships between serum concentrations of $17 \mathrm{OH}$-progesterone and other serum and urinary steroids in patients with congenital adrenal hyperplasia. J Clin Endrocrinol Metab 1978; 46: 98-104.

\section{A Hughes \\ Department of Child Health, Welsh National School of Medicine, Heath Park, Cardiff CF4 $4 X N$}

\section{Dr Frisch comments:}

In our cross-sectional study we merely described the pronounced fluctuations of 17-OHP, testosterone, and cortisol levels in $\mathrm{CAH}$ patients. It was not the aim of the study, nor was it possible, to draw conclusions about the usefulness of such measurements in the long-term therapeutic control, particularly as so far as we are aware, there is no agreement on the extent to which 17-OHP, testosterone, or even urinary pregnantriol should be suppressed in order to obtain optimal growth and development throughout childhood. We think that the finding of perfectly normal levels of these parameters indicates overdosage of corticoid treatment (Cases 2 and 6). 
We agree with Dr Hughes's advocacy of using mainly clinical parameters for treatment control, and that 17-OHP estimations have brought an improvement in monitoring $\mathrm{CAH}$ patients. The correlation of testosterone with 17-OHP levels is well known but as testosterone is less sensitive it can only be a rough guide to inadequate CAH control. Perhaps a longitudinal study, possibly with several centres taking part, could evaluate the various regimens.

\section{Proctoscopy in infancy with reference to its use in necrotising enterocolitis}

\section{Sir,}

I read with interest the paper by Fenton et al., ${ }^{1}$ but wondered why they changed the spelling of the word 'auriscope' which is derived from the Latin auris-ear; thus an auriscope is an instrument designed for examining ears (Medical Dictionary: Faber). According to the
Oxford Dictionary an 'auroscope' therefore is an instrument designed either for looking up the Goddess of the Dawn (Aurora), or for looking up an extinct European wild ox (Aurochs). This is particularly interesting as the technique described requires 'no equipment other than that which is normally to be found on a paediatric ward.'

The editors must control the indiscriminate changing of the spelling of words as they lose their original meaning and the resultant language becomes unintelligible-for example, Archoves of Dosease in Choldhood, or even necrotosing enterocolotos.

Reference
1 Fenton T R, Walker-Smith J A, Harvey D R. Proctoscopy
in infancy with reference to its use in necrotising entero-
colitis. Arch Dis Child 1981; 56: 121-4.
DENNIS A C BARTER
Department of Paediatrics,
New Cross Hospital,
Wolverhampton WV10 OQP,
West Midlands

\section{Book reviews}

Diseases of Children, fourth edition. By Hugh Jolly. (Pp. 689; illustrated + tables. $£ 16.00$ hardback). Blackwell: Oxford. 1981.

It is five years since the last edition was published. This edition has been extensively revised and important and topical material has been added to the neonatal section in particular, while admirable pruning has left the overall size more or less unchanged. This book occupies the middle ground of texts between the short notes approach and the multi-author volume. It is directed at the medical student and general practitioner and will be an effective competitor in this field.

A synoptic view of paediatrics is perhaps no bad thing; the strength of this approach is stressed by the lucid and consistent prose of the author plus the absence of any important gaps or duplication of content, and an appropriate distribution of attention and detail relative to the importance of topics covered is achieved. There are particularly strong areas which are often not well covered by other books of this type, these include the sections on development and assessment, handicap, emotional and behavioural problems, and the minor difficulties of infancy and childhood which cause so much anxiety for parents and family doctors.

Other parts of the book are perhaps not quite so successful; diseases are discussed by systems, but classification is poor, and the background physiology sketchy. Some sections comprise short descriptions of individual conditions with little attempt to tie them together in a more problemorientated approach, and some medical students may not find the transition from preclinical studies particularly easy. No attempt is made to discuss treatment or practical procedures in depth, but there is a sensible and effective paediatric pharmacopeia within the book.

Those within its intended market will appreciate the author's style and description of paediatrics as well as the 140 odd well chosen and adequately reproduced clinical photographs. This book continues to compete effectively in the middle range of paediatric texts, the clarity of print and layout contributing greatly to this, and it can be confidently recommended to all who enjoy a paediatric textbook of the traditional type.

W S UTTLEY
Emotional Disorders in Children and Adolescents. Edited by G P Rooz Sholevar, R M Benson, and B J Blinder. Child Behaviour and Development Series. Series Editor D P Cantwell. (Pp. 710; tables. $£ 35.00$ hardback.) MTP Press: Lancaster. 1980.

This is a large and impressive book with 49 contributors and it concentrates on medical and psychological approaches to treatment. In many ways it is unique in that it concentrates purely on treatment and provides a wide view of the many therapeutic techniques available in child psychiatry including a range of psychotherapeutic interactions, behaviour and drug therapy, and various milieu treatments. The treatments of specific age groups and of specific disorders are considered in separate sections. The difficult topics of treatment of mental handicap and delinquency are presented, together with an interesting chapter on consultation work, and another on biofeedback.

In an all-American work one expects some difference in perspective and terminology but this is not a significant factor in this book. There is a general 